\title{
COLONIALISMO, MIRADAS FRONTERIZAS Y DESNATURALIZACIÓN DE LOS SUSTRATOS EPISTEMOLÓGICOS DEL EUROCENTRISMO
}

\section{Colonialism, Frontier Views, and Changing the Nature of the EPISTEMOLOGICAL UNDERPINNING OF EUROCENTRISM}

Francisco Daniel Tiapa-Blanco*

Resumen: En este ensayo crítico se presenta una serie de reflexiones basadas en la visibilización de los ejes que sostienen los supuestos básicos subyacentes de los sistemas coloniales y neocoloniales. Se parte del principio de que las ideologías dominantes del sistema global se mantienen gracias a la elaboración de discursos ubicuos impuestos como los sustratos epistemológicos de la así llamada "modernidad". La reflexión concluye con la necesidad de otorgar estatus epistemológico a las historias fronterizas como nuevos referentes para la teorización y para la desnaturalización de los discursos opacos y dominantes en el sistema mundo moderno contemporáneo.

Palabras clave: modernidad, eurocentrismo, fronteras culturales, sistema mundo.

Abstract: This critical essay endeavors to make visible the basic assumptions underlying colonial and neo-colonial systems. The main principle posits that the global system's dominant ideologies are maintained by ubiquitous discourses imposed as epistemological underpinnings of so-called modernity. This reflection concludes that it is necessary to recognize the epistemological status of indigenous resistance histories as new referents for the theorization and transformation of dominant and opaque discourses of the Modern World System.

Keywords: modernity, Eurocentrism, cultural frontiers, world system.

\footnotetext{
* Francisco Daniel Tiapa Blanco. Magister Scientiarm en Antropología por el Instituto Venezolano de Investigaciones Científicas, Venezuela. Profesor agregado del Departamento de Antropología y Sociología, Escuela de Historia, Universidad de los Andes, Mérida, Venezuela. Temas de especialización: colonialismo, fronteras étnicas, antropología histórica, diálogos interdisciplinares, geopolíticas del conocimiento, resistencia indígena. Correo electrónico: francisco.tiapa@gmail.com. ORCID: 0000-0005-147-166
}

Enviado a dictamen: 6 de febrero de 2018

Aprobación: 18 de octubre de 2018

Revisiones: 1 


\section{Introducción}

L as bases conceptuales del colonialismo se han reproducido históricamente por medio de un conjunto de supuestos considerados como propios del sentido común dentro del cuerpo de conocimientos que sostienen al asíllamado pensamiento moderno. Con la imposición de una serie de enunciados que parten del principio de que la experiencia histórica del colonialismo es la representación de la condición humana universal, se ha creado un entramado de mitos imbricados en las bases del pensamiento irreflexivo del mundo contemporáneo. Como visión unívoca, el eurocentrismo logra mantenerse como narrativa anónima, bajo una serie de fachadas como los mitos del progreso, la modernidad, la razón o la aldea global. En tal sentido, a fin de construir un nuevo cuerpo discursivo donde el extraordinariamente amplio número de diversidades étnicas y culturales del globo sean capaces de coexistir sin suprimirse mutuamente, es necesario visibilizar la dimensión colonialista y racista de tales entramados. De este modo será posible su relativización $y$, consecuentemente, la apertura de un umbral en el que las múltiples historias y subjetividades veladas por el eurocentrismo puedan desplegarse. En esta orientación relativizante, las historias de resistencia indígena muestran una forma de pensamiento fronterizo, con el estatus epistemológico suficiente para conformarse en el referente de distintas formas de subversión a las actuales condiciones narrativas de existencia del eurocentrismo, el racismo y el patriarcado. En este espacio se presenta una reflexión que va en la dirección planteada y que busca sentar las bases de futuras agendas de trabajo sobre este estatus epistemológico de las distintas formas de resistencia e insurgencia cultural a las hegemonías globales.

Metodológicamente, este ensayo deriva de los referentes de una serie de investigaciones de corte etnográfico e histórico (Tiapa, 2008a, 2008b, 2012), en articulación con la búsqueda de la disolución de los linderos disciplinarios entre antropología e historia por medio de la crítica cultural a los propios referentes vivenciales y simbólicos del analista (Tiapa, 2008b).
En tal articulación, se busca identificar continuidades entre ámbitos perceptivos que, según las posturas clásicas, estarían desconexos. Se parte del principio de que el conocimiento antropológico se puede dirigir tanto a los ámbitos tradicionalmente considerados como aprehensibles desde la etnografía, como a aquellos relacionados con la historia. Asimismo, esta elaboración crítica se dirige a esferas que, por estar demasiado cerca, parecieran encontrarse paradójicamente fuera del rango de reflexión de la antropología, como ocurre con la antropología sobre la mirada del antropólogo.

La unidad de análisis central es lo que instrumentalmente Wallerstein (1976) llama el "sistema mundo moderno", para hacer alusión al conjunto de unidades, ejes y redes globalmente extendidas como resultado de la expansión capitalista de los últimos cinco siglos. Inicialmente, la categoría hace alusión a la configuración de tejidos sociales, flujos de mercancías y relaciones de poder, a lo que se ha sumado el análisis de las representaciones simbólicas (Wolf, 1987), los juegos imaginarios (Gruzinski, 1999; Augé, 1998; Mignolo, 2000), las representaciones de la naturaleza (Coronil, 2000, 2002; Escobar, 1999, 2000) y de configuración colonial de patrones de conocimiento (Lander, 2000a, 2000b; Dussel, 2000).

El orden naturalizado de reflexión se mostrará según un conjunto de vectores que no pretenden agotar el rango de lo posible. Sólo se trata de aquellos que los referentes históricos y etnográficos han sugerido como elementos de relativización del sentido común dominante en el pensamiento contemporáneo. Al decir "dominante" tampoco se quiere decir que sea el único, sino que forma parte del opaco e irreflexivo entramado de representaciones (Geertz, 1996) que en los ámbitos disciplinarios, más allá de la Antropología, han permeado hacia los supuestos básicos subyacentes (Gouldner, 1973) del "sistema mundo moderno". En tal sentido, una crítica a la Antropología y a las disciplinas cercanas no se circunscribe a una reflexión contra estos campos del saber en sí, sino que busca orientarse hacia la cultura de referencia del conocimiento antropológico. Más aún, no sólo a la cultura de referencia, sino a la relación desigual que se establece con las diferentes formas de 
representación cultural de la realidad, en relación con las cuales se construyen las representaciones discursivas en el orden global.

Las historias de resistencia al colonialismo muestran configuraciones narrativas que, por su condición fronteriza, tienen un estatus epistemológico que trasciende los límites del sentido común impuesto por la irreflexividad del eurocentrismo. En el marco del cuerpo narrativo que integra lo que genéricamente se llama "pensamiento moderno", la idea de "epistemología" se conecta con la posibilidad de elaborar enunciados abstractos más allá de las circunscripciones disciplinarias. Este "más allá" permitiría ver el conocimiento como un objeto en sí, a partir de una mirada que trasciende no sólo sus propios límites, sino el constreñimiento cultural que lo genera. En concordancia con las posturas críticas que argumentan en pro de la visibilización de las coacciones de clase (Horkheimer, 1974) y geopolíticas (Said, 2006) de la producción del saber, el contraste entre la historia eurocentrada y las historias de las resistencias fronterizas muestra las dimensiones geoculturales de los sustratos epistemológicos de la producción del discurso histórico. Así, la categoría "geocultura" permite articular el contraste entre diferentes visiones de mundo y la visibilización de las relaciones desiguales, tensas y contradictorias entre esas visiones de mundo con otras historias con las que guardan conexiones mutuamente constitutivas. Su dimensión epistemológica reside en que, más allá de sus contenidos sustantivos, las experiencias de continuidad histórica de identidades negadas por el colonialismo tienen la potencialidad de ser el referente abstracto para la comprensión de otras múltiples formas de subjetividades que, por su existencia misma, son contradictorias con el "deber ser" del patriarcado y el racismo, como dimensiones constitutivas del eurocentrismo.

En este marco reflexivo se tomarán cinco vectores de desnaturalización del pensamiento eurocéntrico. Preliminarmente, es posible enunciar la idea de la unilinealidad del tiempo, junto a la universalización y la abstracción de la experiencia histórica del colonialismo como dos vectores - entre otros - de las metanarrativas
(Lyotard, 1980) que sostienen al entramado discursivo del sistema mundo moderno. Como contraparte, se presentará una reflexión preliminar en torno a las potencialidades teóricas y al estatus epistemológico de las historias fronterizas.

\section{La ubicuidad geocultural de la unilinealidad del tiempo}

El sustrato discursivo del orden globalmente impuesto por el colonialismo se sostiene sobre el sentido unilineal del tiempo. Como un recipiente organizativo, el sentido del tiempo teleológico, progresivo y acumulativo establece las directrices de clasificación y de jerarquización de las diferencias culturales a lo largo del mundo. El discurso de la así llamada modernidad se deriva del esquema de tiempo mítico judeo-cristiano representado en el presente en los mitos bíblicos que comienzan con "una" creación, en "una" sola dirección, hacia el apocalipsis. A fin de naturalizarse, la lógica unilineal del tiempo niega la posibilidad de concebir la asociación entre cultura y geometría del tiempo. De hecho, aunque en buena medida derivó en una construcción culturalmente generada a partir de un proceso histórico colectivo y ausente de voliciones conscientes, la idea del tiempo unilineal tuvo su base política como un constructo históricamente reciente y políticamente orientado por las agencias de las instituciones religiosas de la Europa medieval (Whitrow, 1990).

Con el surgimiento del pensamiento científico, esta geometría del tiempo logró afianzarse por medio de su naturalización al presentarse como una discontinuidad con los relatos religiosos. El esquema de tiempo de la física, la evolución de las especies, la evolución cultural y el mito del progreso se sustentaron en la reproducción formal de este recorrido unilineal y acumulativo (Fabian, 1983). En el ámbito del discurso histórico tradicional, el sentido de la unilinealidad del tiempo se encuentra plasmado en el discurso historicista (Juliá, 1989; Casanova 1991) que, al partir del principio de la existencia "natural" de la historia, establece una perspectiva acrítica en torno a los discursos temporales 
configurados desde el lugar de enunciación dominante. De este modo, una narrativa histórica entre otras, al estar dada y naturalizada, se establece como la única narrativa posible.

Con la expansión colonial, esta estructura mítica se retroalimentó con la representación de la diversidad de formas culturales subyugadas bajo la idea de que la acumulación temporal podría ser visibilizada por medio de la jerarquización política entre pueblos colonizadores y pueblos colonizados. Así, a partir de una "monocultura del tiempo lineal", según la cual la historia tiene un único sentido y dirección, se estableció la lógica de que aquello ajeno a la así llamada "alta cultura" o bien no existe, o bien asume la forma de ignorancia o de incultura (Sousa Santos, 2011: 30).

Estas formas, consideradas inferiores, tendrían como referente empírico a las sociedades indígenas americanas, asumidas como "lo otro" absoluto de las sociedades europeas, las cuales han sido impuestas como representaciones del máximo estadio del progreso humano y como guías para el camino de la civilización (Castro-Gómez, 2000: 154). De este modo, los pueblos indígenas serían la exteriorización en el presente de lo que fue el pasado europeo (Fabian, 1983). Así, desde las mitologías del colonialismo, tal representación actual del pasado se explicaría a partir de la retórica sobre la supuesta incapacidad esencial de las sociedades indígenas para generar cambios en sus propios términos, debido a su limitación para separar sus mentes de sus cuerpos (Chukwudi-Eze, 2001: 207). En esta narrativa, la historia unilineal se ha configurado de una manera tal que no concibe la coexistencia con otras epistemologías del tiempo. Por esa razón, requiere del recurso retórico que traslada a tales epistemologías hacia otro tiempo o hacia un no tiempo, creando la imagen de dos formas culturales esencialmente constituidas y abismalmente separadas, negando cualquier posibilidad de coexistencia entre ellas (Sousa Santos, 2010).

Esta representación cultural del tiempo se convirtió en el principal sustrato de la jerarquización política de las diferencias étnicas en los sistemas coloniales y en el marco de los Estados nacionales, impuestos por las élites neocoloniales en América Latina a partir del siglo XIX en Asia y África a lo largo de la segunda mitad del siglo XX. Sobre la base de la representación de las historias globales encuadradas en el principio de la unilinealidad del tiempo, se elabora la imagen del cambio mundial como un recorrido marcado por las historias de las sociedades europeas. Desde este punto de vista, las otras sociedades se encontrarían en un eterno presente y su cambio sólo podría contemplarse como funcionalmente viable si éste se hace a la manera europea (Dussel, 2000). La alternativa a la imitación europea sería la petrificación en el tiempo, la fragmentación, la involución o bien la desaparición.

\section{La mundialidad concreta del colonialismo y la universalidad abstracta del eurocentrismo}

La posibilidad de que estas representaciones coloniales seirradien de manera ubicua a lolargo del sistema mundo y más allá de contingencias históricas específicas deriva de lo que Dussel llama la confusión entre "mundialidad concreta" y "universalidad abstracta" (Dussel, 2000). En el primer caso se trataría de la realización histórica de los sistemas coloniales, mientras que lo segundo sería el conjunto de entramados discursivos (Foucault, 1977) que presentan las imágenes coloniales como la equivalencia con patrones universales de pensamiento.

Tanto la idea de que la mirada colonial no es una mirada históricamente contingente, sino que puede imponerse como un esquema "universal" de pensamiento, como la idea de que existe una división esencial entre una cultura capaz de cambiar volitivamente, mientras que hay un cuerpo global de culturas petrificadas en el tiempo, concuerdan con el ensamblaje teórico que sostiene que estas divisiones derivan de estructuras ahistóricas e internamente coherentes. Así, según tal cuerpo de ensamblajes dominantes en las ciencias sociales, los componentes de una estructura societal se encuentran dados, pues son el producto de la actuación de agencias previas a las relaciones históricas. En su base irreflexiva, este principio teórico deriva de la secularización de la imagen de un dios providencial (Quijano, 2011), 
como una forma de desplazamiento sustantivo desde el pensamiento mítico hacia una forma dominante de pensamiento científico, que a fin de cuentas no logra separarse de su base religiosa. En este marco mítico, el colonialismo, como sistema cultural, deriva de una serie de experiencias históricas susceptibles de ser relativizadas entre otros múltiples recorridos. En tal sentido, es necesario visibilizar los entramados discursivos de este cuerpo de órdenes, como algo diferente a la "normalidad" o a la correspondencia con una "naturaleza humana" subyacente y suprahistórica. El hecho de que tenga irradiación global no implica que las prácticas e imágenes de los sistemas coloniales y neocoloniales sean la derivación de una teleología planificada que dirige a la aún hoy indiscernible diversidad de expresiones de formas culturales del mundo a un "destino" preestablecido. Esta dirección estaría marcada por el supuesto de que las prácticas de los órdenes coloniales no serían percibidas como la derivación de agencias históricas concretas, sino como la expresión de una "naturaleza humana". A partir del proceso imaginario mediante el cual toda cultura naturaliza sus referentes inmediatos de existencia, estos sistemas, impuestos por medio de la acción explícita de agencias históricas, no sólo se naturalizan, sino que se difuminan al volverse la expresión de lo universal. Así, en la experiencia histórica de configuración del lugar de enunciación colonizante, la imagen de la universalidad logró su máximo punto de abstracción sobre la base de la idea de que este lugar no existe como forma concreta, sino como un punto in-observado de observación, como una conciencia supra-terrenal con capacidades comparables a la deidad (Castro-Gómez, 2007: 83). De este modo, la expresión misma de que una práctica histórico-cultural, entre otras posibles, sea entendida a partir de la imagen del "uni-verso", da cuenta de su profunda raíz mítica. Ésta se conecta con el principio del Uno, de la Verdad Universal, de la conciencia suprema, ominipresente, omnisciente y omnipotente que determina la coherencia y el equilibrio de la heterogeneidad de formas en el cosmos. De allí que una práctica humana, singular y concreta se explique como "lo universal".
Este procedimiento mítico tiene la potencialidad política de deshumanizar un sistema de control, de modo que los sujetos que se encuentran subyugados a él no sólo lo acepten pasivamente, sino que se vuelvan sus defensores activos. De esta manera, se niega la posibilidad de cuestionar su existencia pues no cabe espacio para su relativización. Cualquier intento de cuestionamiento se conecta con otras representaciones, como la del "tiempo progresivo", de modo que, al argumentarse que el orden derivado de los sistemas coloniales no es el único posible, la respuesta se asocia con la idea de que no se puede "retroceder en el tiempo". Es decir, el colonialismo, al ser universal, se impone como un orden frente al cual no hay otra opción de futuro, pues ni siquiera se le puede llamar colonialismo, sino que es en sí la representación de "lo normal". La violencia tangible de la imposición del sentido común de las agencias dominantes del sistema mundo se oculta así por medio de la idea de que es la "Única Verdad". No se trata, en tal sentido, de una verdad sostenida por un argumento convincente, sino porque es la que fue capaz de acompañarse con la represión explícita. Su naturalización pasa por el proceso de la suprahistorización, su mitificación y su irradiación ubicua. De la misma manera que los mitos del capitalismo adquieren fuerza por medio de la condición anónima de la burguesía (Barthes, 1999), la potencia del colonialismo reside en la dificultad de delinear sus contornos. En términos históricos tal difuminación ha pasado por una serie de coyunturas en las que una narrativa se elabora sobre los referentes imaginarios de la anterior. Así, históricamente, por medio de la imposición del cristianismo, el orden del patriarcado fue reafirmado a partir de la deificación de la imagen masculina. Con la conquista de América, la representación genérica de la diversidad cultural del continente posibilitó la creación de una identidad envolvente a partir de la invención de "Europa" como homogeneidad geocultural esencialmente preestablecida (Bernal, 1987). Este nuevo imaginario se nutrió de la narrativa mítica racista, sobre la cual se configuró el imaginario del hemisferio occidental, entendiendo por occidental sólo a las culturas del 
Atlántico Norte y desplazando la heterogeneidad de formas culturales de África, el Caribe y América Latina a la condición de "exterioridad interna" (Mignolo, 2000).

La invención e imposición histórica de esta construcción colonial de identidad pasa necesariamente por la configuración de la imagen de la raza, como entramado discursivo de jerarquización social a partir de la conexión esencial entre piel y cultura. De este modo, la idea de raza, aunque tiene su matriz en el colonialismo, ha probado ser un eje retórico más duradero que el colonialismo en sí (Quijano, 2000), pues ha trascendido por medio de la colonialidad como cuerpo discursivo globalmente naturalizado. En este caso, el racismo se estableció como sustrato identitario del eurocentrismo, pero su enunciación explícita pasó por una serie de entramados consolidados por medio de la caracterización que en el siglo XVIII se hizo sobre la razón (Chukwudi-Eze, 2001). En este sentido, el racismo y el eurocentrismo en el mundo contemporáneo se han velado por medio del cuerpo retórico en que, al mismo tiempo en que se habla de cultura occidental (Coronil, 1999) para hacer alusión a la así llamada "raza blanca" (Mignolo, 2000), se habla de cultura global como una forma de ocultamiento del eurocentrismo (Coronil, 2000) y para hacer alusión a esa "cultura europea" políticamente construida que, a su vez, permitió suprimir el amplio y heterogéneo entramado cultural irradiado al norte de la cuenca del Mediterráneo. En términos de su relación con las historias fronterizas, este juego discursivo lleva a singularizar las historias de resistencia como una subsunción empírica subordinada a las plataformas teóricas derivadas de la historia eurocéntrica. Tal subordinación impediría que estas historias puedan llegar a ser referente lógico para pensar incluso las historias del sistema mundo orientadas a la creación de una sociedad global multicultural. En tal sentido, la visibilización de su dimensión concreta posibilitaría su des-universalización, la inclusión de estas intersecciones y la posibilidad de pensar futuros alternativos, donde tales condiciones limítrofes no necesariamente se ubiquen en las áreas marginales del orden global.

\section{Geopolítica centrífuga e invención de la pasividad de las fronteras del sistema mundo}

En términos de la representación del cambio histórico en el ámbito global, el hecho de que el ego colonial sea la representación de la universalidad y del dinamismo histórico configura una lógica geopolítica centrífuga; es decir, se impone la idea de que desde los centros hegemónicos del sistema mundo se establecen las directrices de los cambios globales de una manera tal que las otras regiones del orden global son la representación de entidades pasivas. Este principio crea la lógica ubicua de que "los otros" — sus otros - sólo cambian en la medida en que imitan a aquellos sujetos capaces de separar sus mentes de sus cuerpos. Las así llamadas fronteras del sistema mundo capitalista o de la modernidad, en tal sentido, serían áreas marginales, por lo que su relevancia para la explicación de los cambios históricos también sería marginal. Corrientes contemporáneas como la etnohistoria, por ejemplo, se orientan hacia la reconstrucción de culturas indígenas esencialmente constituidas en un periodo precolonial, cuando los cambios derivados de los procesos de colonización son presentados como formas de desaparición, degradación o continuidad disminuida por la acción de las sociedades foráneas (Rivera, 2008: 158). Esta mirada ha sido constitutiva de la perspectiva sobre las sociedades indígenas contemporáneas que normaliza el imaginario sobre pueblos "primitivos" y "salvajes" que deben ser domesticados mediante su racionalización (Restrepo, 2007).

Al ser sólo las culturas europeas las que cambian, geopolíticamente esto se expresa en términos de ondas de irradiación desde centros activos hacia periferias pasivas. Sus historias únicamente permiten explicar el pasado "arcaico", "simple", "inocente", "milenario", "tradicional", "ancestral" o "puro" de la historia. Al ser entidades pasivas en el tiempo, sus cambios serían explicables sólo por medio de la indagación de las influencias externas. En los casos en que se admiten sus posibilidades de transformación en términos de sus características culturales intrínsecas, los cambios serían vistos como expresiones provincianas, sin capacidad 
de tener incidencia empírica sobre el resto del orden global. En tal sentido, la negación de lo empírico deriva en negación lógica, pues se cercena el reconocimiento de que tales expresiones sean referente explicativo o proyectivo de otras historias. Esta imposición de la idea de pasividad histórica sobre otras culturas tuvo su base lógica en la construcción de la imagen del sujeto moderno en contraste con múltiples historicidades subsumidas a la condición de objeto. Este último sería relegado a una condición externa al sujeto, debido a la construcción y la imposición de una condición "natural" y "esencial" que lo define como objeto. Sobre esta base, la invención de la singularidad del sujeto, frente a otras entidades, derivó en la negación de relaciones intersubjetivas entre ellos (Quijano, 1992). Así, esta representación se conecta con la ideología racista al derivar de la negación de la capacidad de los "no blancos" de separar sus mentes de sus cuerpos. Al ser sólo cuerpo, se impone la idea de que las sociedades "no europeas" están guiadas por principios irreflexivos de ordenamiento de la realidad que les impiden cualquier decodificación de sus visiones de mundo. Desde este punto de vista, tampoco se reconoce la capacidad de las miradas configuradas desde otras sociedades para descifrar en el cuerpo representaciones que integran y sostienen el sistema mundo. Es decir, este metarrelato, anónimo y ubicuo, sostiene que los no blancos, o aquellos que viven según preceptos culturales no blancos, forman parte de un mundo sobre el cual se habla, pero no "desde donde se habla".

\section{Historias fronterizas y relativización del sentido común eurocéntrico}

Para hacer un contraste entre la potencialidad de las miradas fronterizas y las limitaciones de las metanarrativas eurocéntricas, cabe distinguir entre las miradas monotópicas y las miradas día y pluritópicas (Mignolo, 2001). La conciencia monotópica sería aquella que elabora una representación idealizada de la realidad a partir de una serie de imágenes percibidas como coherentes con su propia vivencia. Así, para la conciencia monotópica, su existencia concreta, sus costumbres, sus proyecciones de futuro y sus relatos sobre el pasado son correspondientes con aquello que su propio contexto establece como el "deber ser". En tal sentido, desde esta conciencia no habría ningún tipo de cuestionamiento a sus principios básicos de ordenamiento de la realidad, pues éstos no se perciben como unos entre muchos, sino como "los únicos posibles". La mirada monotópica es absolutista, pues no se ve en la necesidad de relativizar su orden. Aunque sea capaz de producir conocimiento e incluso tenga la proyección de cuestionar los ámbitos irreflexivos de sus propios referentes culturales, esta mirada percibe a sus referentes vivenciales como la correspondencia con el deber ser y no como una construcción cultural entre otras, pues ni siquiera se considera que sus parámetros de existencia sean humanos. Por el contrario, desde esta mirada lo históricamente contingente y arbitrario, característico de cualquier sistema cultural, se percibe como lo natural. En otras palabras, su condición dominante "naturaliza" sus representaciones imaginarias a tal punto que sus linderos se vuelven imperceptibles.

En el sistema mundomoderno, la mirada eurocéntrica es el marco de elaboración del así llamado pensamiento científico, como un horizonte de "alteridad interna" que busca observar su propio mundo más allá de los linderos se su propia irreflexividad. Se busca ir más allá de lo que se considera que es el estadio religioso (Comte, [1844]2000), el pensamiento vulgar (Durkheim, [1895]1976), la opinión, el sentido común (Bachelard, 2000), entre otras formas de hablar precisamente de esta conciencia "monotópica". Una mirada coherente con el lugar de enunciación dominante no se ubica en otro lugar porque su posicionamiento relacional garantiza al mismo tiempo su posibilidad de producir La Verdad, al mismo tiempo que es una garantía de su condición de poder. Desde la representación naturalizada que distingue entre modos de existencia normales o subnormales, de una manera tal que observarse desde fuera no implicaría ubicarse en "otro lugar", sino ubicarse abajo, atrás o en "la negación del ser". En tal sentido, desde la mirada monotópica la diferencia implica una desigualdad verticalmente ordenada. 
El proceso de configuración de las relaciones coloniales de poder requirió de la configuración de una intersubjetividad, con diferentes direcciones históricas, que la hiciera posible. Por lo tanto, resulta imposible plantearse tal proceso en términos de determinaciones unilineales y unidireccionales. Por el contrario, estas determinaciones tienden a ser “[... recíprocas, heterogéneas, discontinuas, inconsistentes y conflictivas" (Quijano, 2011: 8). De este modo, el primer paso para desuniversalizar el sentido unilineal del tiempo consiste en la provincialización de su cultura de referencia por medio de "[...] la desnaturalización de las narrativas eurocentradas evidenciando la parroquialidad e historicidad de modalidades de pensamiento, de ordenamientos políticos y de prácticas sociales que se esgrimen como universales (Retrepo, 2007: 4). De este modo, la idea de que la historia europea es un proceso centrífugo, en el que sólo Europa es un agente activo mientras que el resto es un cuerpo de entidades pasivas, receptoras de los envíos provenientes desde los centros geopolíticos, es susceptible de ser desmontada. De hecho, las así llamadas periferias son agentes activos de cambio a partir de sus propias historicidades. En tal sentido, el reconocimiento del estatus epistemológico de otras historicidades pasa por superar la "pesadilla de la tradición". Según esta idea, la modernidad sería un estado trascendental y universal, traspasado en su forma esencial a las colonias pasivas, que arrojaría a la condición de "tradición" a aquellas formas culturales que no encajen en el imaginario sobre sí misma (Restrepo, 2007).

Ante las historias fronterizas, la mirada diatópica se constituye por oposición con la monotópica en un doble juego entre relativización de la mirada dominante, pero también de la propia cultura de referencia. Un doble cuestionamiento a partir de la incoherencia entre su propia condición de existencia y de lo que se presenta como "el deber ser". Esta incoherencia coexiste con una vivencia que, aunque es coherente con lo que se dice que es la representación de lo ideal, no es la propia y, además, se encuentra configurada de una manera tal que nunca podrá llegar a ser la propia. Se trata de una manera de estar en el mundo que sólo puede ser observada, posiblemente imitada, pero no puede ser realizada. El hecho de que la mirada monotópica se configure a partir del principio de la coherencia interna de la no relativización la hace ser esencial. Se constituye por medio del principio de la autocontención de las formas. En tal sentido, al no estar abierta al contraste, también constituye una serie de caracterizaciones que simultáneamente se imponen como modelo de imitación, pero al mismo tiempo están elaboradas de una manera en que son inimitables.

Para trascender el esquema colonial y eurocentrado de la historia es necesario abordar otras realidades históricas como entidades en una constante transformación y en contradicción con agencias envolventes de poder (Comaroff y Comaroff, 1992). Más que ser espacios de recepción inerte de los envíos de los así llamados "centros", los contextos fronterizos son marcos de configuración de lógicas intrínsecas donde otras culturas elaboran sus lógicas de cambio a partir de sus propios sistemas del mundo (Sahlins, 1988). Por lo tanto, en lugar de ser el marco de una pasividad histórica ubicada en contextos de no-civilidad, las fronteras son lugares cargados con sus propias historicidades, incluso cuando éstas se encuentren imbuidas en historias de violencia (Taussig, 2002). En tal sentido, más que realidades históricamente pasivas y ancladas en la tradición, las historias fronterizas son múltiples "heterogéneas e incluso conflictivas pulsiones o lógicas de movimiento", pues en ellas hay "necesidades, deseos, intenciones, opciones, decisiones y acciones humanas [...] constantemente, en juego" (Quijano, 2011: 11).

En América Latina, los manuales de urbanismo o los patrones estéticos se elaboran en esta doble dinámica, pues: "[...] como géneros discursivos constituyeron a través de sus leyes y normas un campo policial de vigilancia y ortopedia que captaba e inmovilizaba al ciudadano" (González-Stephan, 1998: 85). Por contraste con estas formas de disciplinamiento del sentido común, la mirada del afuera es diatópica porque es capaz de mirar la realidad hegemónica como algo que, por ser impuesto, debe ser aceptado, incluso en los momentos en que es subvertido. En cierto momento - no necesariamente al final- los 
procesos de descolonización tienden a imponer la necesidad de imitar en algún aspecto al colonizador. La resistencia feminista eventualmente reivindica las diferentes formas en que la mirada masculina impone a la imagen de "la mujer". La resistencia indígena requiere de la apropiación - en el sentido de Bonfil Batalla (1989) - de los elementos culturales de la cultura envolvente para luchar contra ella. Aun así, esos modos de existencia no son percibidos como los propios, pues su diagramación y la elaboración de sus directrices normativas corresponden al otro dominante. Sin embargo, lo propio también es una alteridad, pues desde la mirada de la resistencia se mueve en un ámbito que es negado por las voces dominantes, al mismo tiempo que es reafirmado por la propia voz, pero incluso tiene características internas que llegan a ser cuestionadas. En las historias indígenas, con especial fuerza en el presente, las organizaciones o prácticas llamadas "tradicionales" tienen una condición patrimonial y hasta instrumental. En este sentido, la tradición o ancestralidad no se vive como principio dogmático, sino que, al ser observada, es relativizada y empleada como recurso de reafirmación identitaria ante la envolvencia de los órdenes neocoloniales (Tiapa, 2012).

Sumada a la mirada diatópica se encuentra la mirada pluritópica, como aquella que es capaz no sólo de observar desde afuera su propia realidad y la realidad dominante, sino las múltiples representaciones de otras condiciones de existencia negadas por la mirada hegemónica. Desde este punto de vista, el potencial epistemológico de la resistencia indígena reside en el hecho de que ésta es la condición intrínseca de las dinámicas de construcción de identidades étnicas. Por medio de los procesos de resistencia es posible aprehender una base epistemológica de la subversión cultural al exteriorizarse acciones que dan cuenta de puntos culminantes de procesos de acumulación ideológicos subterráneos que cíclicamente salen a la superficie para expresar continuidades y autonomías en las sociedades indígenas (Rivera, 2008). En tal sentido, otorgar estatus epistemológico a las historias indígenas no implica un retorno al pasado (Sousa Santos, 2011), sino posicionarse en una potencialidad histórica más dinámica que el sentido unilineal del tiempo, pues se trata de una dinámica de cambio que se ha visto en la necesidad de reconfigurarse constantemente. Tampoco se trata de un giro hacia identidades culturales regionalmente circunscritas (Sousa Santos, 2011: 23), sino de reconocer el carácter provinciano de la historia eurocéntrica al mismo tiempo que la condición global y cosmopolita de las historias de resistencia.

En este reconocimiento de la capacidad referencial de las configuraciones históricas fronterizas es necesario desacralizar formas eurocéntricas de autoatribución de exclusividad cognoscitiva y abrir el abanico al reconocimiento de otras formas culturales de pensamiento filosófico, incluso en aquellos contextos donde no se pueda hablar de traducciones literales a la filosofía occidental (Schneewind, 2005). Aún más, el descentramiento del sentido unilineal del tiempo, al otorgar historicidad y dinamismo a los espacios fronterizos, requiere de la apertura hacia otros sentidos del tiempo. Por ejemplo, entre los wayana de Surinam y la Guayana Francesa, los relatos históricos no subordinan el espacio al tiempo, sino a la inversa, pues al hablar de lugares se habla de acontecimientos y recorridos definidos por el espacio en que ocurren; es decir, cada lugar es en sí un tiempo diferente plasmado en el paisaje (Duin, 2012). Entre los huaorani de la Amazonía ecuatoriana, esta espacialización del tiempo lleva a que el recorrido corpóreo en el entorno sea en sí una narrativa temporal (Rival, 2002). Cabe destacar que estas formas de espacialización de la historia se distancian de la lógica colonial, cuyos enunciados se proyectan desde un único lugar, pues se trata de historicidades situadas en múltiples lugares de enunciación.

La mirada hacia otras historicidades puede entenderse como una forma de crítica cultural (Marcus y Fisher, 1986); es decir, en las lógicas de cambio basadas en la contraposición con el discurso uniformizante es posible desestructurar las retóricas de homogeneización dentro de la cultura de referencia del analista. Dado que la aceptación, y simultáneamente la relativización, son características intrínsecas de las miradas fronterizas, la posibilidad de observar otros 
mundos desde afuera se proyecta hacia las múltiples formas de subordinación del sistema mundo moderno. En tal sentido, su potencialidad reside precisamente en su sustrato lógico, en la posibilidad de concatenar coherencias donde las miradas dominantes eirreflexivas son incapaces de concebirlas.

\section{Conclusiones}

Desde las experiencias históricas fronterizas es posible articular un cuerpo perceptivo dirigido a la desnaturalización de los entramados opacos del eurocentrismo. Como conjunto retórico impuesto por la experiencia histórica del colonialismo, el eurocentrismo, más que ser un discurso políticamente consciente, se presenta en el mundo contemporáneo como sentido común de representación de la realidad. En esta dirección, sus principios normativos se orientan a presentar las derivaciones históricas del colonialismo como el ensamblaje de la única realidad posible y, por lo tanto, como representación de la normalidad. De este modo, el colonialismo y el eurocentrismo no se enuncian como singularidades históricas, pues, de hecho, no se enuncian. Por el contrario, discursos opacos cobran fuerza gracias a su condición anónima, pues ésta les permite proyectarse de forma ubicua en ámbitos discursivos que, en una primera instancia, no se presentan como argumentos de legitimación de estos patrones de poder. Dada esta condición anónima y ubicua, el desensamblaje de los metarrelatos del eurocentrismo pasa, necesariamente, por su desnaturalización, es decir, por la exposición explícita de sus enunciados, en particular con énfasis sobre las formas en que éstos se imponen como narrativas identitarias y al mismo tiempo de representación de "los otros".

Entre los metarrelatos ubicuos del eurocentrismo se encuentran ideas como: la unilinealidad del tiempo, la negación de la simultaneidad histórica de "los otros", la representación abstracta de la experiencia histórica del colonialismo, y la imagen de "una" historia global que se irradia desde los centros hacia las periferias de manera centrífuga. Estos vectores de discursividad se proyectan tanto en las esferas culturalmente destinadas a la producción de conocimiento, como en las esferas cotidianas de pensamiento irreflexivo diluidas en la cotidianeidad del mundo contemporáneo.

Elprincipio de la unilinealidad del tiempo se sustenta sobre la base cultural de las mitologías judeocristianas sobre "una sola" historia sucedida a "un" pueblo elegido, donde la deidad marca el único inicio, la trayectoria y el fin. Como ocurre con otras representaciones culturales del tiempo, esta narrativa se establece como la principal base de ordenamiento de otros ámbitos explicativos de la realidad, que en una primera instancia no se presentan como míticos. De este modo, el pensamiento científico, desde la física hasta la sociología, reproducen esta geometría temporal de una manera tal que lo que tuvo un origen religioso, al secularizarse, cobra una fuerza mayor pues se presenta como la máxima expresión de la normalidad. Tal naturalización históricamente ha posibilitado que la experiencia del colonialismo sea legitimada por medio de un sentido teleológico de la historia, en el que la imposición de órdenes coloniales en todo el mundo se presenta como el "destino" a seguir.

La negación de la simultaneidad histórica deriva de la imagen de que las otras culturas carecen de historia, pues se considera que se encuentran estancadas en el tiempo. Independientemente de que haya evidencias contundentes de la capacidad de cambio e innovación por parte de otras sociedades, las retóricas del eurocentrismo se nutren de categorías cuyas connotaciones están cargadas de categorías como "tradición", "ancestralidad", "arcaísmo" o "pureza". La connotación común entre estas categorías es la del "no cambio" o del reconocimiento del cambio siempre que éste sea a la manera en que la mitología el eurocentrismo lo concibe. Al mismo tiempo, en estas categorías subyace la imagen de la esencia autocontenida de estas sociedades, de modo que sus modos de vida son considerados como el derivado de una determinación esencialmente dada.

La universalización del colonialismo permite que su experiencia histórica se naturalice y hasta se oculte, de una manera tal que aquello que fue el resultado de decisiones políticas conscientes se presente como parte 
del curso natural de la historia. Por otra parte, la imagen de "lo universal" proyecta una forma cultural entre otras, como la representación de una normalidad que se encuentra más allá de cualquier tipo de cuestionamiento. Este recurso de invención y de universalización de la europeidad se sustenta sobre la idea de la autocontención de su singularidad histórica, al punto que se niega la posibilidad de asociar la modernidad con el hecho concreto de la condición colonial. En tal sentido, al hablar de lo mundial como lo universal se oculta el hecho de que lo global es en sí mismo lo colonial.

La representación de una historia geopolíticamente centrífuga establece el principio lógico de que únicamente los llamados "centros" globales son capaces de cambiar por medio de su propia volición, mientras que otras regiones del mundo se presentan como periferias pasivas y receptoras de los cambios exógenos. A partir de la idea de que el recorrido temporal está marcado por la europeidad global, irradia la idea de que sólo los centros globales innovan, mientras que las periferias imitadoras, incapaces de pensar en términos de la razón, o bien se mantienen ancladas a la tradición o bien, si cambian, es para desaparecer.

Estos vectores de discursividad del eurocentrismo son susceptibles de ser contrastados con las historias de resistencia al colonialismo. Estas historias han sido configuradas por contraposición a un orden impuesto que no ha sido percibido como la inevitable normalidad, sino como el resultado de decisiones conscientes, diagramadas por agentes de poder. Aún más, desde las historias fronterizas cabe la posibilidad de configurar miradas de relativización al modelo idealizado de existencia impuesto por el eurocentrismo. Al tratarse historias configuradas desde el sentido de la contraposición, el esquema del "único modo de vida posible" es percibido desde la exterioridad. De este modo, el orden hegemónico se observa como uno entre otros, con la única particularidad de que se apoya en instituciones, represiones y retóricas de naturalización. En tal sentido, la teorización desde la mirada fronteriza se puede abordar desde la distinción hecha por Mignolo (2001) entre conciencia monotópica y conciencias dia o pluritópicas. La primera es la conciencia que elabora, vive e impone su modo de vida como la representación del ideal de toda existencia. Al vivir en una constante coherencia entre la vivencia en sí y su deber ser, esta conciencia elabora una mirada uniforme que difícilmente es capaz de relativizarse a sí misma. Por el contrario, las miradas fronterizas, al configurarse en la constante contradicción entre su propia vivencia y el esquema idealizado dominante, son capaces de relativizar tanto este esquema como su propia vivencia. Es decir, se trata de historias que en su misma conformación desnaturalizan el orden opaco e irreflexivo del eurocentrismo.

Como historias fronterizas, las historias de resistencia indígena son una representación de estas miradas pluritópicas. Al ubicarse en un lugar de enunciación donde incluso sus propios modelos culturales se perciben como una exterioridad, la mirada elaborada desde estas historias tiene una potencialidad de innovación, reacomodo, redefinición y cuestionamiento que va más allá de ser sólo un cuerpo narrativo orientado a ilustrar los modelos interpretativos del eurocentrismo. Aún más, desde estas miradas se abre el umbral para una desnaturalización del sentido común del colonialismo susceptible de ser proyectada hacia otras exterioridades, negadas y veladas por la ubicuidad narrativa de los supuestos básicos subyacentes del colonialismo.

\section{Referencias}

Augé, Marc (1998). La guerra de los sueños: ejercicios de etnoficción. Barcelona: Gedisa.

Bachelard, Gaston (2000). La formación del espíritu científico. Madrid: Siglo XXI.

Barthes, Roland (1999). Mitologías. México: Siglo XXI.

Bernal, Martin (1987). Black Athena: The Afroasiatic Roots of Western Civilization. Nueva Brunswick y Nueva Jersey: Rutgers University Press.

Bonfil Batalla, Guillermo (1989). "La teoría del control cultural en el estudio de los procesos étnicos". En Arinsana, 10: 5-36.

Casanova, Julián (1991): La historia social y los historiadores. Barcelona: Crítica. 
Castro-Gómez, Santiago (2000). "Ciencias sociales, violencia epistémica y el problema de la 'invención del otro'". En Edgardo Lander (comp.), La colonialidad del saber: eurocentrismo y ciencias sociales. Perspectivas latinoamericanas. Buenos Aires: CLACSO, pp. 153-172.

Castro-Gómez, Santiago (2007). "Decolonizar la universidad. La hybris del punto cero y el diálogo de saberes". En Santiago Castro-Gómez y Ramón Grosfuguel (eds.), El giro decolonial. Reflexiones para una diversidad epistémica más allá del capitalismo global. Bogotá: Siglo del Hombre Editores.

Chukwudi-Eze, Emmanuel (2001). "El color de la razón: la idea de "raza" en la Antropología de Kant". En Walter Mignolo (ed.), Capitalismo y geopolítica del conocimiento: el eurocentrismo y la filosofía de la liberación en el debate intelectual contemporáneo, t. 2. Buenos Aires: Ediciones del Signo, pp. 201-25l.

Comaroff, John y Jean Comaroff (1992). Ethnography and the Historical Imagination. Boulder, Colorado: Westview Press.

Comte, Augusto ([1844]2000). Discurso sobre el espíritu positivo. Barcelona: Alianza Editorial.

Coronil, Fernando (1999). "Más allá del occidentalismo: hacia categorías geohistóricas no imperiales”. En Casa de las Américas, 39(214): 21-49.

Coronil,Fernando(2000). “Naturalezadelposcolonialismo: del eurocentrismo al globocentrismo”. En Edgardo Lander (comp.), La colonialidad del saber: eurocentrismo y ciencias sociales. Perspectivas latinoamericanas. Buenos Aires: CLACSO, pp. 87-112.

Coronil, Fernando (2002). El Estado mágico: naturaleza, dinero y modernidad. Caracas: Nueva Sociedad.

Duin, Renzo (2012). "Ritual Economy: Dynamic MultiScalar Processes of Socio-Political Landscapes in the Eastern Guiana Highlands". En Antropológica, LVI(117118): 127-174

Durkheim, Emile ([1895]1976). Las reglas del método sociológico. Madrid: Editorial La Pléyade.

Dussel, Enrique (2000). "Europa, modernidad y eurocentrismo". En Edgardo Lander (comp.), La colonialidad del saber: eurocentrismo y ciencias sociales. Perspectivas latinoamericanas. Buenos Aires: CLACSO, pp. 41-54.
Escobar, Arturo (1999). "After Nature: Steps to an Antiessentialist Political Ecology”. En Current Anthropology, 40(1): 1-30.

Escobar, Arturo (2000). "El lugar de la naturaleza y la naturaleza del lugar: globalización o post-desarrollo". En Edgardo Lander (comp.), La colonialidad del saber: eurocentrismo y ciencias sociales. Perspectivas latinoamericanas. Buenos Aires: CLACSO, pp. 113-144.

Fabian, Johanes (1983). Time and the Other. How Anthropology Makes its Object. Nueva York: Columbia University Press.

Foucault, Michel (1977). Las palabras y las cosas. Una arqueología de las ciencias humanas. Madrid: Siglo XXI.

Geertz, Clifford (1996). La interpretación de las culturas. Barcelona: Gedisa.

González-Stephan, Beatriz (1999). "Cuerpos de la nación: cartografías disciplinarias”. En Anales, Nueva Época, 2: 71-106.

Gouldner, Alvin (1973). La crisis en la sociología occidental. Buenos Aires: Amorrortu.

Gruzinski, Serge (1999). La guerra de las imágenes. De Cristóbal Colón a Blade Runner (1492-2019). México: Fondo de Cultura Económica.

Horkheimer, Max (1974). Teoría crítica. Buenos Aires: Amorrortu.

Juliá, Santos (1989). Historia social/Sociología histórica. Madrid: Siglo XXI.

Lander, Edgardo (2000a), “iConocimiento para qué? ¿Conocimiento para quién? Reflexiones sobre la geopolítica de los saberes hegemónicos". En Revista Venezolana de Economía y Ciencias Sociales, 6(2): 53-72.

Lander, Edgardo (comp.) (2000b). La colonialidad del saber: eurocentrismo y ciencias sociales. Perspectivas latinoamericanas. Buenos Aires: CLACSO.

Lyotard, Jean François (1980). La condición posmoderna. Barcelona: Tecnos.

Marcus, George y Michael Fisher (1986). Anthropology as Cultural Critique. An Experimental Moment in the Human Sciences. Chicago: The University of Chicago Press.

Mignolo, Walter (2000). "La colonialidad a lo largo y a lo ancho: el hemisferio occidental en el horizonte colonial de la modernidad". En Edgardo Lander (comp.), La colonialidad del saber: eurocentrismo y ciencias 
sociales. Perspectivas latinoamericanas. Buenos Aires: CLACSO.

Mignolo, Walter (2001). Capitalismo y geopolítica del conocimiento: el eurocentrismo y la filosofía de la liberación en el debate intelectual contemporáneo. Buenos Aires: Ediciones del Signo.

Quijano, Aníbal (1992). “Colonialidad y modernidad/ racionalidad". En Perú Indígena, 13(29): 11-20.

Quijano, Anibal (2000). "Colonialidad del poder, eurocentrismo y América Latina”. En Edgardo Lander (comp.), La colonialidad del saber: eurocentrismo y ciencias sociales. Perspectivas latinoamericanas. Buenos Aires: CLACSO, pp. 201-246.

Quijano, Anibal (2011). "Colonialidad del poder y clasificación social". En Contextualizaciones Latinoamericanas, 1(5): 1-33.

Restrepo, Eduardo (2007). "Antropología y colonialidad". En Santiago Castro-Gómez y Ramón Grosfoguel (comps.), El giro decolonial. Reflexiones para una diversidad epistémica más allá del capitalismo global. Bogotá: Siglo del Hombre Editores, Universidad Central, Instituto de Estudios Sociales Contemporáneos, Pontificia Universidad Javeriana e Instituto Pensar, pp. 289-304.

Rival, Laura (2002). Trekking Through History: The Huaorani of Amazonian Ecuador. Nueva York: Columbia University Press.

Rivera Cusicanqui, Silvia (2008). "Elpotencialepistemológico y teórico de la historia oral: de la lógica instrumental a la descolonización de la historia". En Alejandro Rosillo Martínez et al., Teoria crítica dos direitos humanos no século XXI. Porto Alegre: EDIPUCRS, pp. 154-175.

Sahlins, Marshall (1988). "Cosmologies of Capitalism: The Trans-Pacific Sector of the World System". En Proceedings of the British Academy, 74: 1-51.
Said, Edward (2006). Orientalismo. Barcelona: Debolsillo.

Schneewind, Jerome B. (2005). "Globalization and the History of Philosophy". En Journal of the History of Ideas, 66(2): 169-178.

Sousa Santos, Boaventura de (2010). Descolonizar el saber, reinventar el poder. Montevideo: Trilce.

Sousa Santos, Boaventura de (2011). "Epistemologías del sur". En Utopía y Praxis Latinoamericana. Revista Internacional de Filosofía Iberoamericana y Teoría Social, 16(54), julio-septiembre: 17-39.

Taussig, Michael (2002). Chamanismo, colonialismo y el hombre salvaje: un estudio sobre el terror y la cultura. Bogotá: Editorial Norma.

Tiapa, Francisco (2008a) "Resistencia indígena e identidades fronterizas en la colonización del Oriente de Venezuela, siglos XVI-XVIII". En Antropológica, 109: 69-112. Caracas.

Tiapa, Francisco (2008b). "Antropología, historia colonial y descolonización del pasado". En Revista Venezolana de Economía y Ciencias Sociales, 14(1): 13-29.

Tiapa, Francisco (2012). "Identidad étnica y patrimonio cultural entre los Kari'ña de la Mesa de Guanipa". En Presente y Pasado. Revista de Historia, 17(34): 115-132. Wallerstein, Immanuel (1976). The Modern World System I. Capitalist Agriculture and the Origins of the European World-Economy in the Sixteenth Century. Nueva York: Academic Press.

Whitrow, Gerald J. (1990). El tiempo en la historia: La evolución de nuestro sentido del tiempo y de la perspectiva temporal. Barcelona: Crítica.

Wolf, Eric (1987). Europa y la gente sin historia. México: Fondo de Cultura Económica. 